Open Access

\title{
Effect of exercises with weight vests and a patient education programme for women with osteopenia and a healed wrist fracture: a randomized, controlled trial of the OsteoACTIVE programme
}

\author{
K. A. Hakestad ${ }^{1 *}$, M. K. Torstveit ${ }^{2}$, L. Nordsletten ${ }^{1,4}$ and M. A. Risberg ${ }^{1,3}$
}

\begin{abstract}
Background: Exercise programmes have shown to be important for the prevention of fractures in patients with established osteoporosis. However, few studies have evaluated the effect of such programmes for women with low bone mineral density (BMD) (osteoporosis or osteopenia) who have already suffered a fracture. Studies have indicated that exercise programmes concentrating on muscular strength and dynamic balance have a positive effect on significant risk factors for falls such as quadriceps strength and balance. The aim of the present study was to assess the effect of a 6-month exercise programme and a patient education component (OsteoACTIVE) on quadriceps strength, BMD, dynamic balance, walking capacity, physical activity level and quality of life in postmenopausal women with osteopenia and a previous wrist fracture.

Methods: Eighty postmenopausal women with low BMD and a healed wrist fracture were randomized to OsteoACTIVE $(n=42)$ (age 65.5, range 51.2-79.2 years) or patient education only (control group) $(n=38)$ (age 63.9, range 52.7-86.8 years). Follow-up was conducted after 6 months (end of intervention) and 1 year. Outcome measures included quadriceps strength, BMD, dynamic balance, walking capacity, physical activity level and quality of life.

Results: Thirty-five participants ( $83 \%$ ) completed the OsteoACTIVE programme. Mean adherence to OsteoACTIVE was $87 \%$ (range $48-100 \%$ ). Twenty-five participants (72 \%) met the a priori goal of $80 \%$ adherence to the program. No adverse events were reported. There were no significant differences between the two groups over the 1-year follow-up for any of the outcome measures.

Conclusion: The OsteoACTIVE rehabilitation programme revealed no significant effect on quadriceps strength, BMD, dynamic balance, walking capacity or self-reported functional outcomes over the 1-year follow-up.

Trial registration: NCT01357278 at ClinicalTrials.gov (date of registration2010-04-21).

Keywords: Osteopenia, Quadriceps strength, Weight vest, Exercise, Rehabilitation
\end{abstract}

\footnotetext{
* Correspondence: k.a.hakestad@medisin.uio.no
'Department of Orthopaedic Surgery, Norwegian Research Center for Active

* Correspondence: K.a.hakestad@medisin.uio.no
'Department of Orthopaedic Surgery, Norwegian Research Center for Active

Rehabilitation (NAR), Oslo University Hospital, Trondheimsveien 235, 0514
Oslo, Norway

Rehabilitation (NAR), Oslo University Hospital, Trondheimsveien 235, 0514
Oslo, Norway

Full list of author information is available at the end of the article
}

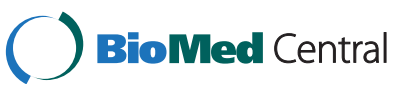

(C) 2015 Hakestad et al. Open Access This article is distributed under the terms of the Creative Commons Attribution 4.0 International License (http://creativecommons.org/licenses/by/4.0/), which permits unrestricted use, distribution, and reproduction in any medium, provided you give appropriate credit to the original author(s) and the source, provide a link to the Creative Commons license, and indicate if changes were made. The Creative Commons Public Domain Dedication waiver (http://creativecommons.org/publicdomain/zero/1.0/) applies to the data made available in this article, unless otherwise stated. 


\section{Background}

Osteopenia or osteoporosis is a progressive disease of the skeleton characterized by low bone mass and microarchitectural deterioration of bone tissue resulting in an increased risk of fragility fractures [1]. Fragility fractures lead to physical disability, a great deal of pain, impaired quality of life (QoL), increased mortality and higher health-care cost [2-4]. A previous wrist fracture is a risk factor for future vertebral or hip fractures with a relative risk of 4.4 and 1.9, respectively [5]. Among those already who have sustained a fracture, $50 \%$ will experience a new fracture within a ten-year period [6]. Furthermore, there is an increased tendency to fall in elderly patients with reduced muscle strength and balance [7].

Physical activity has shown to increase muscle strength and bone mineral density (BMD) [8]. Furthermore, physical activity provides improved muscle control, balance and co-ordination and reduces the risk of falls [8]. Active rehabilitation in the form of structured exercise programmes may be one of the most important factors for the prevention of fractures due to low $\operatorname{BMD}[9,10]$. Several RCTs have found positive effects of weightbearing activities to reduce falls and fracture risk, as well as to maintain or increase BMD in postmenopausal women with low BMD [7, 9-13]. In addition, structured exercise programmes in postmenopausal women with low BMD have shown to improve QoL [14].

Progressive high-intensity resistance exercises have shown to improve physical function and muscle strength in older adults $[15,16]$. Progressive loading during weight-bearing activities may be effective in improving BMD in patients with low BMD [17]. The doseresponse relationship between loading and improvements in BMD is nevertheless unknown [17]. The use of weight vests during exercise in individuals with low BMD without a fracture, has to our knowledge been reported in two studies $[18,19]$. These studies reported significant improvements in muscle strength and balance, but no change in BMD [18, 19]. Weight vests could be used to increase loading on the spine and the lower extremities, with the goal of increasing load to the skeletal system and improving muscle strength [20], in older adults with low BMD.

Most studies on exercise interventions have examined women with normal healthy bones or low BMD [11, 12], but very few studies have included women with low BMD and previous fractures [21-23]. To our knowledge, no studies have used weight vests in patients with low BMD and a recent fracture.

Therefore, the main aim of this study was to evaluate the effect after 1 year of a 6-month active rehabilitation programme with the use of weight vests and including a patient education programme (OsteoACTIVE) on quadriceps strength, BMD, dynamic balance, walking capacity, physical activity level and QoL in postmenopausal women with osteopenia and a previous wrist fracture.

\section{METHODS}

\section{Participants}

The study was a single-blinded, randomized controlled study (https://clinicaltrials.gov/ct2/ show/ NCT01357278?term $=$ NCT01357278\&rank $=1$ reference number NCT01357278 (date of registration 2010-0421). The participants were included from the Department of Orthopaedic Surgery and the Emergency Ward at the Oslo University Hospital in Norway. We included (1) postmenopausal women $>50$ years of age, (2) diagnosed with low BMD (t-score $<-1.5$ ), (3) wrist fracture not older than 2 years and healed at inclusion (no plaster cast), and (4) domiciled in the Oslo region. They were excluded if they (1) had had hip- or vertebral fractures, (2) history of $>3$ osteoporotic fractures, (3) problems/illness indicating that active rehabilitation was not advisable, (4) were moderately or intensely physically active for more than $4 \mathrm{~h}$ per week, (5) were unable to understand written or spoken Norwegian.

All participants received oral and written information about the study and signed informed consent. The study was approved by the Regional Medical Research Ethics Committee of South- East Norway (reference number 1.2005.82), and conducted in accordance with the Helsinki Declaration. The study has adhered to the CONSORT guidelines.

\section{Intervention}

The OsteoACTIVE rehabilitation programme consisted of a 6-month exercise programme combined with a patient education component (OsteoINFO). The exercise programme consisted of 2 group exercise sessions and one home exercise session per week (in total $3 \times 60 \mathrm{~min} /$ week). The exercise programme had a progression of intensity and types of exercises, and was based on an established model developed at the University of British Columbia, Canada (Osteofit) [22, 24], and a Danish model [23]. Briefly, the main component of the exercises consisted of strength, balance, coordination and core stability exercises including weight vests. The exercises included in the OsteoACTIVE programme have previously been published by our group [25]. The patient education component (OsteoINFO) was based on the programme entitled "Choises for Better Bone Health" [26], and was offered twice, and each session lasted for two hours in both groups. The main component of the OsteoINFO programme comprised What is osteoporosis?, Risk factors for osteoporosis, Nutrition for bone health?, Fall prevention and General exercise guidelines. Participants allocated to the control group, who only received the OsteoINFO, were requested not to alter their original lifestyle habits. 


\section{Measurements}

Isokinetic quadriceps strength was the main outcome measure and was examined with a Biodex 6000 isokinetic dynamometer (Biodex 3 System Pro, USA). Peak torque in Newton metres $(\mathrm{Nm})$ at $60^{\circ}$ and total work in Joules $(\mathrm{J})$ at $180^{\circ}$ per second were measured. We have previously reported reliability data for isokinetic muscle strength tests and found high inter- and intra-rater reliability (ICC 0.890.93) in postmenopausal women with osteopenia [27].

Anthropometry Body mass index (BMI) was calculated with weight/(height $\mathrm{x}$ height). Absolute and percentage fat, fat-free mass and BMD were measured with dual-energy X-ray absorptiometry (DXA) (GE Lunar Prodigy and ENCORE Version 11.2: GE Healthcare, Waukesha, WI). The minimal detectable changes in BMD have shown to be $0.4 \mathrm{~g} / \mathrm{cm}^{2}$ at the lumbar spine and $0.2 \mathrm{~g} / \mathrm{cm}^{2}$ at the hip [28]. The scanned areas were the hip, femoral neck and trochanter, lumbar spine and total body.

Dynamic balance was evaluated with the four square step test (FSST) identifying those who were at risk of falls [29]. Cut-off score $>15 \mathrm{~s}$ has been established for multiple fallers ( 2 or more falls within the last 6 months, and $<15 \mathrm{~s}$ for non-multiple fallers (fewer than 2 falls within the last 6 months) in older adults $>65$ years of age [29]. The FSST has been found to be reliable $($ ICC $=0.99)$ and has a sensitivity and specificity of 85 and $88-100 \%$, respectively [29].

Walking capacity was measured with the six-minute walk test [30]. It has been validated to measure functional capacity in older adults [30]. To demonstrate clinical relevance, an improvement of $54 \mathrm{~m}$ is required [31]. The level of perceived exertion was recorded using the Borg scale (score range, 6-20, with 6 indicating "very easy" and 20 "very exhausting"), and was used after the six-minute walk test [32]. An improvement of 2 units on the Borg scale has been considered to be significant [33].

Physical activity level was evaluated using the validated self-reported Physical Activity Scale for the Elderly (PASE) $[34,35]$. The modified Norwegian version on a scale from 0 to 315 was used, where 0 represents not active and 315 represents extremely active [36].

Health-related QoL was evaluated using the Medical Outcomes Study 36-item Short-Form Health Survey (SF-36) [37]. The questionnaire is divided into 8 subscales, each scored on a scale from 0 to 100 . SF-36 includes aspects of physical function, role limitationsphysical, bodily pain, general health, vitality, social function, role limitations-emotional and mental health. Studies have reported high reliability and validity [38], and an improvement of 3-5 points has been considered clinically relevant [39].

Data were collected at baseline, at 6 months and at 1 -year follow-up by an independent investigator who was blinded to treatment allocation. The participants were asked to record their leisure-time physical activity level in a training diary. Adverse events were recorded in the training diary and the medical record.

\section{Sample size calculation}

The power calculations were based on the primary outcome, quadriceps strength. With a clinically relevant difference between the groups for quadriceps isokinetic strength test of $10 \%$ from baseline to 6 months, and a standard deviation for quadriceps strength of $12 \mathrm{Nm}$ [40], 30 patients were needed in each group in order to achieve a statistical power of $90 \%$ and a significance level of 0.05 . Allowing for drop-out, 40 patients were included in each group.

\section{Randomization and blinding}

Block randomization with blocks of 6, using sealed envelopes in series, was prepared by the statistician. A research coordinator, who was not involved in the testing or intervention, opened sealed envelopes containing the randomization allocation and assigned subjects to the OsteoACTIVE group or control group, accordingly. The assessor was blinded to group allocation throughout the trial and analysis period.

\section{Data analysis}

To evaluate between group differences, a linear mixed model (variance component structure with time and time* group as fixed effects and time as random effect intercept and slope) was used $\left(\mathrm{IBM}^{\ominus}\right.$ SPSS $^{\ominus}$ Statistics, version 20.0 (IBM Corp., Somers, New York, USA). Intention- to-treat analysis was used to compare the OsteoACTIVE group and the control group [41]. Significance level was set to 0.05 . The data are presented as mean difference $(95 \% \mathrm{CI})$ between groups at 6 months and 1-year follow-up. The 6-month intervention, with 2 weekly supervised group exercise sessions, consisted of maximum 48 group exercise sessions. The acceptable adherence to the exercise group was set to $80 \%$ attendance rate, which represented 38 group exercise sessions.

\section{Results}

A total of 194 women were screened and eligible for participation, after which 80 women were enrolled and assessed (Fig. 1). Of the 80 women, 42 were randomly assigned to the OsteoACTIVE and 38 to the control group (Fig. 1). Of the 42 participants who were included in the OsteoACTIVE group, 3 withdrew informed consent prior to testing after the 6-month intervention. Total hip replacement, severe knee osteoarthritis and personal reasons prevented 3 other participants from completing the intervention programme. One additional participant was lost to follow-up, leaving 35 who completed the intervention programme (83\%). At 1-year follow-up, 4 participants 


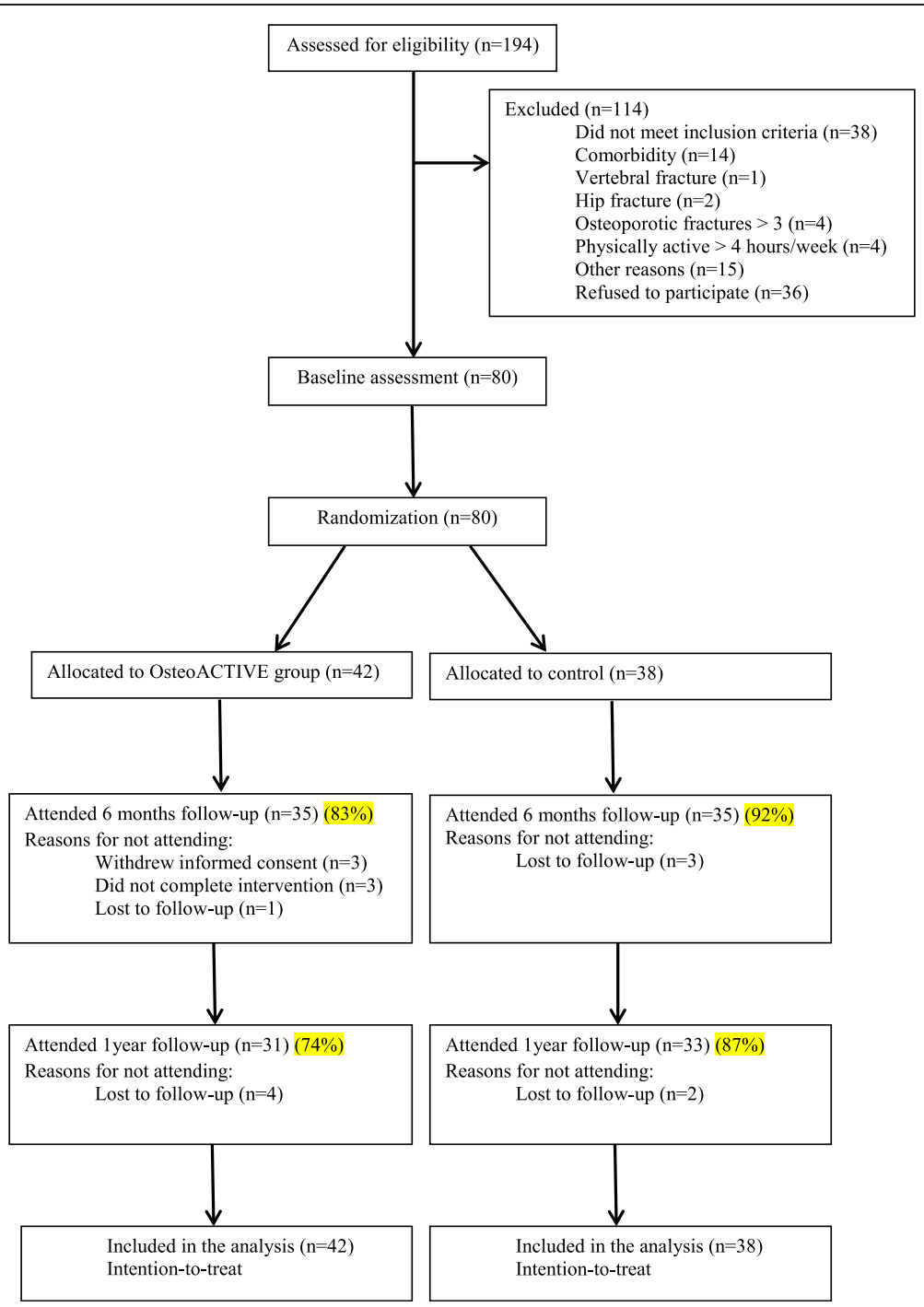

Fig. 1 Flow-chart of the study

were lost to follow-up (74 \%) $(n=31)$ (Fig. 1). In the control group, 3 participants were lost to follow-up (92\%) $(n=35)$ at 6 months (Fig. 1). At 1-year follow-up, 2 additional participants were dropped out $(87 \%)(n=$ 33) (Fig. 1). The mean adherence rate for the 35 participants who completed the intervention was $87 \%$ (range 48-100\%). Altogether 25 participants (72\%) met the a priori goal of $80 \%$ adherence, while 10 participants (28\%) were below the $80 \%$ attendance rate. No adverse events were reported by the participants in the OsteoACTIVE group.

The OsteoACTIVE and the control groups were similar at baseline with regard to age, height, weight, BMI, age of menopause, years since postmenopause, physical activity level and education (Table 1). The mean years since the time of fracture were 1.6 years $(0.9)$ in the
OsteoACTIVE group and 1.5 years $(0.8)$ in the control group.

Over the 1-year follow-up no difference was found between the OsteoACTIVE group and the control group for the main outcome quadriceps strength (Table 2). Furthermore, no significant differences were found for any of the secondary outcome measures between the groups (Table 2).

In general, the estimated means for the OsteoACTIVE group improved or were stable over the follow-up period, except for the decreased quadriceps strength at total work in the right limb and BMD at the lumbar spine and at the femoral trochanter (Table 3). For the control group, the estimated means mainly decreased over the follow-up period, except for some of the variables for quadriceps strength (Table 3). 
Table 1 Baseline characteristics of the participants

\begin{tabular}{|c|c|c|}
\hline & $\begin{array}{l}\text { OsteoACTIVE group } \\
(n=42)\end{array}$ & $\begin{array}{l}\text { Control group } \\
(n=38)\end{array}$ \\
\hline Age (years) & $65.5 \pm 7.1$ & $63.9 \pm 7.1$ \\
\hline Height (cm) & $164.6 \pm 6.3$ & $164.4 \pm 5.2$ \\
\hline Weight (kg) & $65.4 \pm 10.6$ & $66.2 \pm 8.3$ \\
\hline Body mass index $\left(\mathrm{kg} / \mathrm{cm}^{2}\right)$ & $24.2 \pm 4.1$ & $24.3 \pm 2.8$ \\
\hline Body fat (kg) & $23.4 \pm 6.6$ & $23.7 \pm 6.6$ \\
\hline Body fat (\%) & $36.4 \pm 5.6$ & $36.6 \pm 6.1$ \\
\hline Lean mass (kg) & $39.7 \pm 4.7$ & $40.1 \pm 3.9$ \\
\hline Age of menarche (years) & $13.3 \pm 1.5$ & $13.1 \pm 1.7$ \\
\hline Age of menopause (years) & $48.7 \pm 4.6$ & $50.3 \pm 4.1$ \\
\hline Time since menopause (years) & $16.7 \pm 8.7$ & $13.6 \pm 8.3$ \\
\hline Current use of bisphosphonate, $\mathrm{n}(\%)$ & $9(21.4)$ & $14(36.8)$ \\
\hline Current use of calcium, n (\%) & $2(4.8)$ & $2(5.3)$ \\
\hline Time since fracture by inclusion (years) & $1.6 \pm 0.9$ & $1.5 \pm 0.8$ \\
\hline Past history of fracture (years) ${ }^{a}$ & $2(1-3)$ & $2(0-3)$ \\
\hline Family history of osteoporosis, n (\%) & $28(66.7)$ & $28(73.7)$ \\
\hline Current smoker, n (\%) & $4(4.9)$ & $5(13.2)$ \\
\hline Previous smoker, n (\%) & $13(31)$ & $12(31.6)$ \\
\hline Current alcohol use (4-7 units/week), n (\%) & $8(19)$ & $5(13.2)$ \\
\hline \multicolumn{3}{|l|}{ Educational attainment, n (\%) } \\
\hline Higher degree >3 (years) & $14(33.3)$ & $14(36.8)$ \\
\hline Lower degree <3 (years) & $28(66.7)$ & $24(63.2)$ \\
\hline PASE $(0-315)^{b}$ & $103.1 \pm 56.7$ & $114.6 \pm 58.7$ \\
\hline
\end{tabular}

Values are mean \pm SD unless otherwise indicated

${ }^{a}$ Value is median (minimum-maximum)

${ }^{b}$ PASE, The Physical Activity Scale for the Elderly

\section{Discussion}

No significant differences between the OsteoACTIVE group and the control group were found for quadriceps strength, BMD, dynamic balance, walking capacity, physical activity level and QoL over the 1-year follow-up.

Our active rehabilitation programme, OsteoACTIVE, followed the recommended treatment guidelines for postmenopausal women with osteoporosis [42]. The guidelines consisted of weight-bearing activities to improve muscle strength, maintain or increase BMD and balance, prevent falls and fractures, reduce pain and focus on healthy lifestyle, and reduce risk factors for falls. The adherence to the active rehabilitation programme was $87 \%$ where $72 \%$ of the participants fulfilled the a priori goal of $80 \%$ adherence. Our result for adherence is in line with other comparable studies with intervention duration of 6 months [9]. According to Howe et al. [9], adherence is one of the main factors that influence the effectiveness of exercise interventions.

In our study, no significant differences in quadriceps strength between the OsteoACTIVE group and the control group were detected over the 1-year follow-up. However, the OsteoACTIVE group maintained increased quadriceps strength at peak torque $60 \%$ sith $9.8 \%$ (right limb) and $13 \%$ (left limb) at the 1-year follow-up. Also, the control group maintained quadriceps strength, but somewhat less (1.8\% in the right limb and $5.8 \%$ in the left limb). These improvements in quadriceps strength are in line with those reported in the systematic review by deKam et al. [11], who found 3-28 \% improvements in quadriceps strength in elderly persons with low BMD who followed an exercise programme with a duration of $12-30$ weeks. The explanations for maintained quadriceps strength could be neural adaption and learning effect [43]. Furthermore, it appears that our 6-month active rehabilitation programme had a positive benefit on quadriceps strength without any formal exercise intervention at the 1-year follow-up. Moreover, our intervention seemed to act as a motivation for being more physically active, in light of the increased quadriceps strength that was maintained at the 1-year follow-up. The OsteoINFO with its component of General exercise guidelines may have influenced the control group to be more physically active. Despite no significant difference in physical activity level measured with PASE between 
Table 2 Mean difference (95\% Cl) between the OsteoACTIVE group and the control group at 6 months and 1-year follow-up

\begin{tabular}{|c|c|c|c|}
\hline & 6 months & 1 year & $p$-value \\
\hline \multicolumn{4}{|l|}{ Quadriceps strength } \\
\hline Right peak torque $60^{\circ}(\mathrm{Nm})$ & $-2.9(-14.9,9.0)$ & $6.9(-5.5,19.4)$ & 0.692 \\
\hline Left peak torque $60^{\circ}(\mathrm{Nm})$ & $0.7(-11.2,12.6)$ & $6.2(-6.0,18.5)$ & 0.792 \\
\hline Right total work $180^{\circ}(\mathrm{J})$ & $93.4(-74.9,261.7)$ & $110.9(-63.7,285.8)$ & 0.431 \\
\hline Left total work $180^{\circ}(\mathrm{J})$ & $43.1(-125.5,211.9)$ & $77.8(-96.1,251.8)$ & 0.789 \\
\hline \multicolumn{4}{|l|}{$B M D \mathrm{~g} / \mathrm{cm}^{2}$} \\
\hline Lumbar spine (L1-L4) & $-.02(-.07, .02)$ & $-.00(-.05, .04)$ & 0.818 \\
\hline Hip total & $.01(-.02, .06)$ & $.02(-.02, .06)$ & 0.615 \\
\hline Femoral neck & $.01(-.02, .05)$ & $.02(-.01, .06)$ & 0.428 \\
\hline Femoral trochanter & $.00(-.03, .04)$ & $.01(-.03, .05)$ & 0.954 \\
\hline \multicolumn{4}{|l|}{ Physical capacity } \\
\hline FSST (sec) & $.4(-1.8,2.6)$ & $-.4(-2.7,1.8)$ & 0.767 \\
\hline $6 \mathrm{MWT}(\mathrm{m})$ & $41.5(-1.6,84.7)$ & $11.3(-33.1,84.7)$ & 0.273 \\
\hline Borg's scale & $0.3(-0.7,1.4)$ & $0.8(-0.3,1.9)$ & 0.280 \\
\hline PASE (0-315) & $1.5(-26.3,29.4)$ & $24.2(-4.8,53.4)$ & 0.328 \\
\hline \multicolumn{4}{|l|}{ SF-36 } \\
\hline Physical functioning & $-2.7(-10.2,4.8)$ & $-3.2(-11.1,4.6)$ & 0.130 \\
\hline Role limitations-physical & $-1.2(-13.6,11.1)$ & $3.5(-9.3,16.5)$ & 0.109 \\
\hline Bodily pain & $-1.6(-13.2,9.9)$ & $-3.1(-15.2,8.9)$ & 0.545 \\
\hline General health perceptions & $-5.2(-15.1,4.5)$ & $-1.6(-11.9,8.6)$ & 0.708 \\
\hline Vitality & $1.0(-9.2,11.4)$ & $-.3(-11.1,10.4)$ & 0.995 \\
\hline Social functioning & $-3.9(-13.9,6.1)$ & $5.4(-4.9,15.9)$ & 0.404 \\
\hline Role limitations-emotional & $-4.5(-14.3,5.3)$ & $2.1(-8.0,12.4)$ & 0.523 \\
\hline Mental health & $.1(-7.9,8.2)$ & $2.6(-5.8,11.2)$ & 0.937 \\
\hline
\end{tabular}

Values are given as estimated mean group difference $(95 \% \mathrm{Cl})$

Linear mixed model (variance component model) with time and time*group as fixed effects, and time as random effect intercept and slope

Cl confidence interval, Nm Newton meter, J Joule, BMD bone mineral density, FSST four square step test, 6MWT six-minute walk test, PASE physical activity scale

for the elderly

the groups, the OsteoACTIVE group had an activity level in favour of the control group that was 24.2 points higher at the 1-year follow-up. Our results are supported by RCT conducted by Pereira et al. [44] where they found higher levels of physical activity in the intervention group than the control group 10 years after cessation of the intervention. Despite no significant differences in BMD between our groups, BMD in the spine, total hip, femoral neck and femoral trochanter tended to be stable at the 1year follow-up for the OsteoACTIVE group (from 1.5 to $1.7 \%$ ). This is in accordance with the meta-analysis by Howe et al. [9], who found a positive change of $1 \%$, but no statistical significant improvements. Previous studies have shown that to gain BMD in postmenopausal women, a period of at least 12-18 months of weight training is recommended [42, 45, 46]. Moreover, we found no clinically significant changes for BMD in the spine or in the hip. Both groups included bisphosphonate users $(n=9$ in the OsteoACTIVE group, $n=14$ in the control group), which may have masked the effect of the exercise.
In our study, no statistically significant differences in dynamic balance were found between the groups. An RCT in postmenopausal women with low BMD, conducted by Giaonudis et al. [47], found significant differences between the groups in dynamic balance using the FSST. One explanation of the significant effect on FSST in their study could be the duration of their intervention, which was 18 months, whereas we only studied a 6-month programme. Another explanation could be that our participants were below the cut-off score for multiple fallers, indicating that the FSST was not sensitive to detecting changes over time. Nevertheless, it is unknown whether the FSST is sensitive to change over time $[29,48]$. Participants in our study did not differ in walking capacity assessed by the six-minute walk test. This could be due to a ceiling effect already at baseline compared to healthy elderly [49]. In addition, to obtain a clinically significant change, an improvement of $54 \mathrm{~m}$ had to be achieved [31]. Mean scores for all subscales of the SF-36 were higher compared to 
Table 3 Descriptive statistics of the outcome measures at baseline, 6 months and 1-year follow-up for the OsteoACTIVE group and the control group

\begin{tabular}{|c|c|c|c|c|c|c|c|c|c|c|c|c|}
\hline & \multicolumn{6}{|c|}{ OsteoACTIVE group } & \multicolumn{6}{|c|}{ Control group } \\
\hline & $N$ & Baseline & N & 6 months & $N$ & 1 years & $N$ & Baseline & $N$ & 6 months & $N$ & 1 year \\
\hline \multicolumn{13}{|l|}{ Quadriceps strength } \\
\hline $\begin{array}{l}\text { Right peak torque } 60^{\circ} \\
(\mathrm{Nm})\end{array}$ & 42 & $95.1 \pm 29.1$ & 35 & $98.1 \pm 25.6$ & 31 & $104.4 \pm 22.7$ & 38 & $95.7 \pm 24.7$ & 33 & $101.0 \pm 21.6$ & 32 & $97.4 \pm 24.0$ \\
\hline Left peak torque $60^{\circ}(\mathrm{Nm})$ & 42 & $87.9 \pm 24.6$ & 34 & $93.3 \pm 23.8$ & 31 & $99.7 \pm 25.9$ & 38 & $88.6 \pm 24.5$ & 33 & $92.6 \pm 24.0$ & 32 & $93.7 \pm 25.8$ \\
\hline Right total work $180^{\circ}(\mathrm{J})$ & 42 & $\begin{array}{l}1181.4 \pm \\
374.4\end{array}$ & 35 & $\begin{array}{l}1325.5 \pm \\
368.5\end{array}$ & 31 & $\begin{array}{l}1323.6 \pm \\
339.5\end{array}$ & 38 & $\begin{array}{l}1182.6 \pm \\
337.3\end{array}$ & 33 & $\begin{array}{l}1232.2 \pm \\
318.3\end{array}$ & 32 & $\begin{array}{l}1212.7 \pm \\
363.2\end{array}$ \\
\hline Left total work $180^{\circ}(\mathrm{J})$ & 42 & $\begin{array}{l}1091.7 \pm \\
344.6\end{array}$ & 34 & $\begin{array}{l}1204.7 \pm \\
369.7\end{array}$ & 31 & $\begin{array}{l}1236.5 \pm \\
341.7\end{array}$ & 38 & $\begin{array}{l}1081.1 \pm \\
341.7\end{array}$ & 33 & $\begin{array}{l}1161.5 \pm \\
347.0\end{array}$ & 32 & $\begin{array}{l}1164.4 \pm \\
361.1\end{array}$ \\
\hline \multicolumn{13}{|l|}{$B M D \mathrm{~g} / \mathrm{cm}^{2}$} \\
\hline Lumbar spine $\left(L_{1}-L_{4}\right)$ & 42 & $0.951 \pm 0.139$ & 35 & $0.943 \pm 0.114$ & 31 & $0.950 \pm 0.110$ & 38 & $0.955 \pm 0.088$ & 33 & $0.968 \pm 0.084$ & 33 & $0.955 \pm 0.095$ \\
\hline Hip total & 42 & $0.807 \pm 0.079$ & 35 & $0.822 \pm 0.081$ & 31 & $0.821 \pm 0.088$ & 38 & $0.793 \pm 0.099$ & 34 & $0.806 \pm 0.102$ & 33 & $0.799 \pm 0.109$ \\
\hline Femoral neck & 42 & $0.781 \pm 0.077$ & 35 & $0.795 \pm 0.085$ & 31 & $0.793 \pm 0.081$ & 38 & $0.767 \pm 0.078$ & 34 & $0.777 \pm 0.083$ & 33 & $0.769 \pm 0.094$ \\
\hline Femoral trochanter & 42 & $0.644 \pm 0.071$ & 35 & $0.664 \pm 0.077$ & 31 & $0.654 \pm 0.085$ & 38 & $0.641 \pm 0.099$ & 34 & $0.658 \pm 0.091$ & 33 & $0.643 \pm 0.103$ \\
\hline \multicolumn{13}{|l|}{ Physical capacity } \\
\hline FSST (sec) & 42 & $10.9 \pm 8.9$ & 34 & $9.0 \pm 3.7$ & 31 & $7.9 \pm 2.5$ & 38 & $9.9 \pm 2.6$ & 34 & $8.6 \pm 1.9$ & 33 & $8.3 \pm 2.5$ \\
\hline $6 \mathrm{MWT}(\mathrm{m})$ & 42 & $592.8 \pm 82.8$ & 34 & $608.5 \pm 94.5$ & 31 & $596.1 \pm 87.3$ & 38 & $598.2 \pm 101.1$ & 34 & $567.0 \pm 83.8$ & 33 & $584.8 \pm 90.5$ \\
\hline Borg's scale & 42 & $10.4 \pm 2.3$ & 34 & $10.7 \pm 2.7$ & 31 & $10.8 \pm 2.3$ & 38 & $9.8 \pm 2.2$ & 34 & $10.4 \pm 1.9$ & 33 & $9.9 \pm 2.4$ \\
\hline PASE (0-315) & 42 & $103.1 \pm 56.7$ & 35 & $123.8 \pm 59.4$ & 31 & $129.1 \pm 60.6$ & 38 & $114.6 \pm 58.7$ & 35 & $122.3 \pm 65.0$ & 33 & $104.8 \pm 53.7$ \\
\hline \multicolumn{13}{|l|}{ SF-36 } \\
\hline Physical functioning & 42 & $82.3 \pm 16.7$ & 35 & $84.1 \pm 18.7$ & 31 & $84.5 \pm 14.1$ & 38 & $90.0 \pm 11.7$ & 35 & $86.8 \pm 20.0$ & 33 & $87.7 \pm 12.0$ \\
\hline Role limitations-physical & 42 & $71.4 \pm 31.3$ & 35 & $81.6 \pm 26.8$ & 31 & $83.8 \pm 21.5$ & 38 & $85.5 \pm 21.9$ & 35 & $82.8 \pm 26.4$ & 33 & $80.3 \pm 26.1$ \\
\hline Bodily pain & 42 & $70.0 \pm 23.1$ & 35 & $76.0 \pm 25.0$ & 31 & $74.9 \pm 22.5$ & 38 & $77.4 \pm 22.3$ & 35 & $77.6 \pm 26.1$ & 33 & $78.0 \pm 27.7$ \\
\hline General health perceptions & 42 & $72.0 \pm 18.2$ & 35 & $70.4 \pm 22.7$ & 31 & $72.7 \pm 20.8$ & 38 & $73.9 \pm 21.3$ & 35 & $75.7 \pm 21.0$ & 33 & $74.3 \pm 21.2$ \\
\hline Vitality & 42 & $56.8 \pm 21.1$ & 35 & $61.2 \pm 21.5$ & 31 & $62.7 \pm 18.8$ & 38 & $57.5 \pm 22.7$ & 35 & $60.1 \pm 22.8$ & 33 & $63.0 \pm 23.5$ \\
\hline Social functioning & 42 & $82.1 \pm 21.0$ & 35 & $83.2 \pm 24.4$ & 31 & $90.3 \pm 19.6$ & 38 & $87.5 \pm 19.9$ & 35 & $87.1 \pm 22.3$ & 33 & $84.8 \pm 22.9$ \\
\hline Role limitations-emotional & 42 & $84.7 \pm 22.9$ & 35 & $87.6 \pm 22.8$ & 31 & $90.3 \pm 19.6$ & 38 & $89.9 \pm 19.0$ & 35 & $92.1 \pm 14.9$ & 33 & $88.1 \pm 23.6$ \\
\hline Mental health & 42 & $77.6 \pm 14.9$ & 35 & $78.7 \pm 16.5$ & 31 & $81.7 \pm 13.3$ & 38 & $76.9 \pm 19.5$ & 35 & $78.5 \pm 18.4$ & 33 & $79.0 \pm 19.4$ \\
\hline
\end{tabular}

Values are mean \pm SD

Cl confidence interval, $\mathrm{Nm}$ Newton meter, J Joule, BMD bone mineral density; FSST four square step test, $6 M W T$ six-minute walk test, PASE physical activity scale for the elderly

age-matched population scores at baseline [50], and no improvements were found. A meta-analysis by Li et al. [14], has suggested that SF-36 may not be sensitive to detecting changes resulting from an intervention, and that a disease-specific questionnaire could be more appropriate for individuals with low BMD.

Patient education has been demonstrated to improve medication compliance and persistence across a broad range of conditions and disease severity [51], but it remains uncertain whether or not patient education also improves compliance in exercise interventions for osteoporotic patients.

\section{Strengths and limitations}

To our knowledge, this is the first study evaluating the effect of an exercise programme with the use of weight vests in women with low BMD and a previous fracture. Furthermore, our study is one of few studies that have investigated the long-term effect of an exercise intervention among women with low BMD.

We did not monitor number of falls, which constitutes a limitation in this study. Another limitation is the low adherence to reporting physical activity level in the training diary. We may therefore have lost useful information about physical activity habits outside of the group exercise sessions during the 6-month rehabilitation programme. The results could also be a consequence of participants changing their behaviour when entering the study, i.e. the Hawthorne effect [52]. Since only 25 participants met the a priori goal of $80 \%$ adherence to the active rehabilitation programme, we could not perform a per-protocol analysis because it would be underpowered [41]. Furthemore, per 
protocol analysis may be prone to bias because the reasons for not following the treatment may be attributed to the treatment [41]. Our participants seemed to have better function and QoL compared to previously reported data for healthy elderly persons. Hence, significant improvement in function and QoL may be limited.

\section{Conclusion}

We found no significant effects of a 6-month active rehabilitation programme including a patient education component (OsteoACTIVE) in postmenopausal women with low BMD and a healed wrist fracture over a 1-year follow-up.

\section{Abbreviations}

BMD: bone mineral density; QoL: quality of life; Nm: Newton metres; J: Joules; ICC: intra-class correlation coefficient; BMI: body mass index; DXA: dual-energy $x$-ray absorptiometry; FSST: four square step test; PASE: physical activity level for the elderly; SF-36: short form 36; 6MWT: sixminute walk test; SD: standard deviation; Cl: confidence interval; $\mathrm{RCT}$ : randomized, controlled trial.

\section{Competing interests}

The authors declare that they have no competing interests.

\section{Authors' contributions}

MKT, LN and MAR participated in the design of the study, contributed to drafting the article and read and approved the final manuscript. MKT carried out the OsteolNFO. KAH carried out the patient inclusion, administered the questionnaires, performed all the physical examinations and conducted the statistical analysis. All the authors read and approved the final manuscript.

\section{Acknowledgements}

The study was funded by grants from South-Eastern Norway Regional Health Authority. We also acknowledge the Norwegian Sport Medicine Clinic, Oslo, Norway for supporting the Norwegian Research Center for Active Rehabilitation with rehabilitation facilities and research staff. The Norwegian Research Center for Active Rehabilitation is a collaboration between the Norwegian School of Sport Sciences, the Department of Orthopaedic Surgery, Oslo University Hospital and the Norwegian Sports Medicine Clinic. We also acknowledge Åsa Axelsson, Kristin Bølstad, Marte Lund and Annika Storevold as instructors for the exercise group.

\section{Author details \\ ${ }^{1}$ Department of Orthopaedic Surgery, Norwegian Research Center for Active Rehabilitation (NAR), Oslo University Hospital, Trondheimsveien 235, 0514 Oslo, Norway. ${ }^{2}$ Faculty of Health and Sport Sciences, University of Agder, Kristiansand and Grimstand, Norway. ${ }^{3}$ Department of Sports Medicine, Norwegian School of Sport Sciences, Oslo, Norway. ${ }^{4}$ University of Oslo, Oslo, Norway.}

\section{Received: 8 July 2015 Accepted: 10 November 2015}

Published online: 14 November 2015

\section{References}

1. WHO Scientific group. Prevention and managment of osteoporosis: report of WHO scientific group. 2003. Report No.: WHO Technical Report Series 2003: Vol. 921

2. Kanis JA. Assessment of fracture risk and its application to screening for postmenopausal osteoporosis: synopsis of a WHO report. WHO Study Group. Osteoporos Int. 1994:4(6):368-81.

3. Osnes EK, Lofthus CM, Meyer HE, Falch JA, Nordsletten L, Cappelen IF, et al. Consequences of hip fracture on activities of daily life and residential needs. Osteoporos Int. 2004;15:567-74.

4. Pasco JA, Sanders KM, Hoekstra FM, Henry MJ, Nicholson GC, Kotowicz MA The human cost of fracture. Osteoporos Int. 2005;16:2046-52.
5. Klotzbuecher CM, Ross PD, Landsman PB, Abbott III TA, Berger M. Patients with prior fractures have an increased risk of future fractures: a summary of the literature and statistical synthesis. J Bone Miner Res. 2000;15(4):721-39.

6. Kanis JA, Johnell O, Oden A, Dawson A, De Laet C, Jonsson B. Ten year probabilities of osteoporotic fractures according to BMD and diagnostic thresholds. Osteoporos Int. 2001;12:989-95.

7. Pfeifer $M$, Sinaki M, Geusens $P$, Boonen S, Preisinger $E$, Minne HW. Musculoskeletal rehabilitation in osteoporosis: a review. J Bone Miner Res. 2004;19(8):1208-14.

8. Kahn K, McKay H, Kannus R, Bailey D, Wark J, Bennel K. Physical Activity and Bone Health. USA: Human Kinetics; 2001

9. 9 Howe TE, Shea B, Dawson LJ, Downie F, Murray A, Ross C, et al. Exercise for preventing and treating osteoporosis in postmenopausal women. Cochrane Database Syst Rev. 2011;CD000333. doi: 10.1002/14651858. CD000333.pub2

10. 10 Karlsson MK- Nordqvist A, Nordqvist A, Karlsson C. Physical activity, muscle function, falls and fractures. Food Nutr (Roma) 2008;52. doi: 10.3402/ fnr.v52i0.1920.

11. de Kam D, Smulders E, Weerdesteyn V, Smits-Engelsman BC. Exercise interventions to reduce fall-related fractures and their risk factors in individuals with low bone density: a systematic review of randomized controlled trials. Osteoporos Int. 2009;20:2111-25.

12. Gillespie LD, Gillespie WJ, Robertson MC, Lamb SE, Cumming RG, Rowe BH. Interventions for preventing falls in elderly people. Cochrane Database Syst Rev. 2003;4:CD000340.

13. Howe $T E$, Rochester $L$, Neil F, Skelton DA, Ballinger C. Exercise for improving balance in older people. Cochrane Database Syst Rev. 2011;9(11):CD004963.

14. Li WC, Chen YC, Yang RS, Tsauo JY. Effects of exercise programmes on quality of life in osteoporotic and osteopenic postmenopausal women: a systematic review and meta-analysis. Clin Rehabil. 2009;23(10):888-96.

15. Liu CJ, Latham N. Progressive resistance strength training for improving physical function in older adults. Cochrane Database Syst Rev. 2009;8(3): CD002759.

16. Peterson MD, Rhea MR, Sen A, Gordon PM. Resistance exercise for muscular strength in older adults: a meta-analysis. Ageing Res Rev. 2010;9(3):226-37.

17. Vuori IM. Dose-response of physical activity and low back pain, osteoarthritis, and osteoporosis. Med Sci Sports Exerc. 2001;33(6):551-86.

18. Shaw JM, Snow CM. Weighted vest exercise improves indices of fall risk in older women. J Gerontol A Biol Sci Med Sci. 1998;53(1):M53-8.

19. Snow CM, Shaw JM, Winters KM, Witzke KA. Long-term exercise using weighted vests prevents hip bone loss in postmenopausal women. J Gerontol A Biol Sci Med Sci. 2000;55(9):M489-91.

20. Puthoff ML, Darter B, Nielsen DH, Yack HJ. The effect of weighted vest walking on metabolic responses and ground reaction forces. Med Sci Sports Exerc. 2006;38(4):746-52.

21. Bergstrom I, Landgren B, Brinck J, Freyschuss B. Physical training preserves bone mineral density in postmenopausal women with forearm fractures and low bone mineral density. Osteoporos Int. 2008;19(2):177-83.

22. Carter ND, Khan KM, McKay HA, Petit MA, Waterman C, Heinonen A, et al. Community-based exercise program reduces risk factors for falls in 65- to 75-year-old women with osteoporosis: randomized controlled trial. CMAJ. 2002;167(9):997-1004.

23. Malmros B, Mortensen $L$, Jensen MB, Charles P. Positive effects of physiotherapy on chronic pain and performance in osteoporosis. Osteoporos Int. 1998:8(9):215-21.

24. Carter ND, Khan KM, Mallinson A, Janssen PA, Heinonen A, Petit MA, et al. Knee extension strength is a significant determinant of static and dynamic balance as well as quality of life in older community-dwelling women with osteoporosis. Gerontology. 2002;48(6):360-8.

25. Hakestad KA, Torstveit MK, Nordsletten L, Axelsson AC, Risberg MA. Exercises including weight vests and a patient education program for women with osteopenia: a feasibility study of the OsteoACTIVE rehabilitation program. J Orthop Sports Phys Ther. 2015;10(1-36):97.

26. Gold DT, Silverman SL. Osteoporosis self-management: choices for better bone health. South Med J. 2004;97(6):551-4.

27. Eitzen I, Hakestad KA, Risberg MA. Inter- and intrarater reliability of isokinetic thigh muscle strength tests in postmenopausal women with osteopenia. Arch Phys Med Rehabil. 2012;93(3):420-7.

28. Lodder MC, Lems WF, Ader HJ, Marthinsen AE, van Coeverden SC, Lips P, et al. Reproducibility of bone mineral density measurement in daily practice. Ann Rheum Dis. 2004;63(3):285-9. 
29. Dite W, Temple VA. A clinical test of stepping and change of direction to identify multiple falling older adults. Arch Phys Med Rehabil. 2002; 83(110003-9993 (Print)):1566-71.

30. Enright PL. The six-minute walk test. Respir Care. 2003;100(4):783-5.

31. WIse RA, Brown CD. Minimal clinically important differences in the sixminute walk test and the incremental shuttle walking test. COPD. 2005;2(1): 125-9.

32. Borg GA. Psychophysical bases of perceived exertion. Med Sci Sports Exerc. 1982;14(5):377-81.

33. Ries AL. Minimally clinically important difference for the UCSD Shortness of Breath Questionnaire, Borg Scale, and Visual Analog Scale. COPD. 2005;2(1): 105-10.

34. Dinger MK, Oman RF, Taylor EL, Vesely SK, Able J. Stability and convergent validity of the Physical Activity Scale for the Elderly (PASE). J Sports Med Phys Fitness. 2004;44(2):186-92.

35. Washburn RA, Smith KW, Jette AM, Janney CA. The Physical Activity Scale for the Elderly (PASE): development and evaluation. J Clin Epidemiol. 1993; 46(2):153-62.

36. Loland N. Reliability of the physical activity scale for the elderly (PASE). Eur J Sport Sci. 2002;2(5):1-12.

37. Ware Jr JE, The SCD, MOS. 36-item short-form health survey (SF-36). I. Conceptual framework and item selection. Med Care. 1992;30(6):473-83.

38. McHorney CA, Ware Jr JE, Lu JF, Sherbourne CD. The MOS 36-item Short-Form Health Survey (SF-36): III. Tests of data quality, scaling assumptions, and reliability across diverse patient groups. Med Care. 1994;32(1):40-66.

39. Hays RD, Woolley JM. The concept of clinically meaningful difference in health-related quality-of-life research. How meaningful is it? Pharmacoeconomics. 2000;18(5):419-23.

40. Risberg MA. Evaluation of knee function after anterior cruciate ligament reconstruction. Oslo: Surgical Clinic, Ullevaal Hospital, University of Oslo; 1999.

41. Gupta SK. Intention-to-treat concept: a review. Perspect Clin Res. 2011;2(3): 109-12.

42. Bonaiuti D, Arioli GF, Diana G, Franchignoni F, Giustini A, Monticone M, et al. SIMFER Rehabilitation treatment guidelines in postmenopausal and senile osteoporosis. Eura Medicophys. 2005;41(4):315-37.

43. Sayers SP. High-speed power training: a novel approach to resistance training in older men and women. A brief review and pilot study. J Strength Cond Res. 2007;21(2):518-26.

44. Pereira MA, Kriska AM, Day RD, Cauley JA, LaPorte RE, Kuller LH. A randomized walking trial in postmenopausal women: effects on physical activity and health 10 years later. Arch Intern Med. 1998;158:1695-701.

45. Guadalupe-Grau AF, Fuentes TF, Guerra BF, Calbet JA. Exercise and bone mass in adults. Sports Med. 2009;39(6):439-68.

46. Kelley GA, Kelley KS, Tran ZV. Resistance training and bone mineral density in women: a meta-analysis of controlled trials. Am J Phys Med Rehabil. 2001;80(1):65-77.

47. Gianoudis J, Bailey CA, Ebeling PR, Nowson CA, Sanders KM, Hill KF, et al. Effects of a targeted multimodal exercise program incorporating high-speed power training on falls and fracture risk factors in older adults: a community-based randomized controlled trial. J Bone Miner Res. 2014;29(1): 182-91.

48. Whitney SL, Marchetti GF, Morris LO, Sparto PJ. The reliability and validity of the four square step test for people with balance deficits secondary to a vestibular disorder. Arch Phys Med Rehabil. 2007:88(1):99-104.

49. ATS statement: guidelines for the six-minute walk test. Am J Respiratory Clin Care Med. 2002:166(1):111-7.

50. Loge JH, Kaasa S. Short form 36 (SF-36) health survey: normative data from the general Norwegian population. Scand J Soc Med. 1998;26(4):250-8.

51. Gold DT, McClung B. Approaches to patient education: emphasizing the long-term value of compliance and persistence. Am J Med. 2006;119(4 Suppl 1):S32-7.

52. McCambridge J, Witton J, Elbourne D. Systematic review of the Hawthorne effect: new concepts are needed to study research participation effects. J Clin Epidemiol. 2014;67(3):267-77.

\section{Submit your next manuscript to BioMed Central and take full advantage of:}

- Convenient online submission

- Thorough peer review

- No space constraints or color figure charges

- Immediate publication on acceptance

- Inclusion in PubMed, CAS, Scopus and Google Scholar

- Research which is freely available for redistribution

Submit your manuscript at www.biomedcentral.com/submit
C Biomed Central 